\title{
O Sentimento do mundo: Fichte leitor de Rousseau e Kant
}

\section{Glauber Cesar Klein}

\section{OpenEdition}

Journals

Edição electrónica

URL: http://journals.openedition.org/ref/513

DOI: $10.4000 /$ ref.513

ISSN: 2258-014X

Editora

EuroPhilosophie Editions

\section{Refêrencia eletrónica}

Glauber Cesar Klein, "O Sentimento do mundo: Fichte leitor de Rousseau e Kant », Revista de Estud(i)os sobre Fichte [Online], 8 | 2014, posto online no dia 21 setembro 2014, consultado o 08 setembro 2020. URL : http://journals.openedition.org/ref/513; DOI : https://doi.org/10.4000/ref.513

Este documento foi criado de forma automática no dia 8 setembro 2020

(c) EuroPhilosophie 


\title{
O Sentimento do mundo: Fichte leitor de Rousseau e Kant
}

\author{
Glauber Cesar Klein
}

Havemos de amanhecer. 0 mundo se tinge com as tintas da antemanhã e o sangue que escorre é doce, de tão necessário para colorir tuas pálidas faces, aurora. ${ }^{1}$

\section{0 sentimento originário e a resposta de Fichte ao problema da coisa-em-si}

1 Sumariamente, podemos apontar como ponto nevrálgico da crítica de Jacobi a Kant na segunda das objeções por ele formuladas em seu David Hume sobre a crença, ou idealismo $e$ realismo, um diálogo ${ }^{2}$. A tese de que a atividade de nossas faculdades de conhecimento depende da afecção de objetos externos é inconsequente com outra tese fundamental de Kant, a saber, que só temos acesso a fenômenos, pois coisas em si são incognoscíveis.

2 Na Introdução $0^{3}$ à Crítica da razão Pura, entre outras passagens, ${ }^{4}$ Kant afirma que todo o nosso conhecimento depende de objetos que afetem ${ }^{5}$ nossos sentidos, apenas a partir do que temos representações e atividade de nossa faculdade intelectual. Essa tese kantiana, contudo, parece contradizer outras passagens da mesma obra, nomeadamente os resultados da Analítica Transcendental, segundo os quais as categorias - entre elas, a de causalidade - só têm validade quando limitadas à esfera fenomênica, o que vale dizer que as categorias não têm um uso válido quando se pretende conhecer as coisas-em-si-mesmas e o suposto papel delas no começo do conhecimento sensível.

3 Jacobi alega então que, para não sucumbir às consequências de um fenomenalismo fechado, portanto, à acusação de idealismo no sentido dogmático, Kant acaba por aceitar uma tese realista que, por sua vez, contradiz momentos fundamentais de sua teoria:

"Creio que isto é o suficiente para provar que a filosofia Kantiana abandona completamente o espírito de seu sistema quando diz dos objetos que estes 
impressionam os sentidos, em virtude do que provocam sensações [Empfindungen erregen] e assim suscitam representações [Vorstellungen]: pois, segundo a doutrina kantiana, o objeto empírico, que é sempre apenas fenômeno, não pode existir fora de nós, e não pode ser outra coisa que uma representação; do objeto transcendental [transcendentaler Gegenstand], no entanto, não sabemos sequer o mínimo; e não se trata dele, em absoluto, ao se considerar os objetos [Gegenstände]; seu conceito é, ademais, um conceito problemático, o qual repousa sobre a forma do nosso pensamento, completamente subjetivo correspondente à sensibilidade que nos é característica; a experiência não lhe dá nada, e não pode, de forma alguma, dar-lhe alguma coisa, posto que aquilo que não é fenômeno, nunca pode ser um objeto da experiência; o fenômeno, no entanto, e esta ou aquela afecção [Affection] da sensibilidade em mim, não constitui qualquer referência de tais representações a um objeto [Object] qualquer" ${ }^{6}$.

Contudo, a despeito de uma aparente contradição, Kant tem de partir da postulação de objetos que "provocam impressões, dando lugar desse modo às representações", pois do contrário não é possível explicar como temos representações, caso não se queira, como é o caso de Kant, derivá-las do próprio sujeito; assim, sem este ponto de partida o idealismo transcendental não poderia se auto sustentar ${ }^{7}$. Se por um lado a tese da incognoscibilidade das coisas-em-si nos condena às meras representações, por outro lado as representações nos levam a admitir coisas-em-si sendo causas das mesmas, o que contradiz a tese da incognoscibilidade das coisas-em-si-mesmas, uma vez que admitir esta afecção externa supõe conhecimento, a saber, pressupõe saber que coisas existem fora das representações que provocam. Esta postulação, no entanto, parece se valer de um procedimento que o próprio Kant acusa de ser o erro da metafísica dogmática, qual seja, aceitar a existência de objetos independentes do sujeito.

5 Também sumariamente, podemos entender do seguinte modo a réplica a Jacobi por parte de Reinhold8: As coisas-em-si não podem ser conhecidas, podem, porém, ser pensadas. Mais, devem ser pensadas:

[...] tal como os próprios objectos representáveis, as coisas em si também não podem ser negadas. Elas são esses mesmos objectos, na medida em que estes não são representáveis. Constituem esse algo que é o fundamento, exterior à representação, da matéria de uma representação...9

6 Com isso, é saliente a posição reinholdiana sobre a inutilidade da coisa-em-si para o conhecimento positivo, determinante, a necessidade do conceito numênico de coisaem-si para a reflexão transcendental, reflexionante. Se estivermos corretos, o argumento de Reinhold funda-se na consideração da unidade do objeto tomado ora como fenômeno, ora como coisa-em-si; trata-se sempre de atermo-nos às nossas representações; mas estas mesmas representações são - do ponto de vista oposto ainda assim um objeto numênico da nossa consideração reflexionante sobre o objeto do conhecimento. Negar que só temos a ver com representações, seria o dogmatismo dos realistas transcendentais; negar que o conceito de coisa-em-si seja necessário enquanto conceito-limite da possibilidade de todo conhecimento humano, seria o dogmatismo dos idealistas empíricos. A lição kantiana, na voz de Reinhold, diz: Não é possível ser realista, tampouco idealista, mas é preciso ser ambos: ideal-realismo, real-idealismo filosofia transcendental. E, como ser real-idealista e ideal-realista, em suma, filósofo transcendental, sem ser contraditório? - Tomando a distinção entre fenômenos e coisas-em-si em sua verdadeira significação: Só temos a ver com representações (idealismo transcendental/realismo empírico), mas dentro da análise das representações é possível distinguir as representações em classes (conceito, intuição) e tipos (ideia da razão, categoria do entendimento, conceito empírico, conceito lógico, 
etc.; intuição formal, forma da intuição, intuição sensível, intuição intelectual, etc.), e assim distinguir as representações objetivas (conceitos e intuições) das meramente subjetivas (conceito vazio, intuição cega); mas estas mesmas representações, se são representações, são representação de algo, que, no entanto, não é objeto externo às representações (no sentido de algo toto genere diverso, embora seja exterior à representação na medida que só pode ser pensado a partir da abstração das condições transcendentais subjetivas do conhecimento humano), mas o mesmo objeto que aparece na representação agora tomado em outra significação, a de ser uma coisa-em-si, enquanto conceito necessário da razão para dar acabamento sistemático ao edifício do nosso conhecimento empírico, admitindo assim o conceito problemático de númeno.

7 A nosso ver, este argumento reinholdiano é impecável, mas limitado. Impecável, para responder à objeção de Garve: se só temos a ver com nossas representações, a filosofia transcendental é um idealismo superior ${ }^{10}$, isto é, empírico, como o de Berkeley, e o conceito de coisa-em-si é arbitrário e contraditório. Limitado para responder, pelo menos, a uma questão de Jacobi: Kant precisa admitir e admite claramente que coisasem-si afetam os nossos sentidos e, assim, proporcionam a matéria das nossas sensações, que serão formalizadas pelas intuições e pelos conceitos, para construir o conhecimento objetivo, mas, ao mesmo tempo, se admite isso, nega outra tese capital da filosofia transcendental e da distinção entre fenômeno e coisa-em-si: as categorias do entendimento, que Kant justificou a validade necessária e universal na Dedução das categorias do entendimento, por isso mesmo só tem validade quando aplicadas única e exclusivamente às representações sensíveis. Kant aqui, afirma Jacobi, não é apenas circular, é também e sobretudo contraditório.

8 Em outras palavras, segundo Jacobi e seu "problema da coisa-em-si" (que tem uma estrutura tripla, como vimos, mas cuja tese forte é a do problema da afecção), ainda que Kant não seja nem cético nem idealista empírico (eis as outras duas objeções da tríplice objeção jacobiana), ele continua a ser algo bem pior, contraditório. Daí a conclusão de Jacobi, o idealista transcendental "tem que negar as coisas-em-si" e "afirmar o idealismo mais forte que já existiu".

Disso, chegaremos à seguinte constatação: a contra objeção reinholdiana responde perfeitamente à objeção de Garve, mas nem arranha a objeção das afecções de Jacobi. E, à seguinte proposta de tese de leitura da solução fichtiana ao problema da coisa-em-si: Para Fichte, a solução ao problema de Jacobi, que ao mesmo tempo muda a contra objeção a Garve, é: Não temos a ver apenas com representações - ideias, intuições e conceitos -, o temos apenas do ponto de vista teórico; temos a ver também com sentimentos, isto do ponto de vista prático; e é do ponto de vista prático que o problema de Jacobi - o problema das afecções - é resolvido: não somos afetados pelas coisas-em-si, pois sem dúvida "afecção" é um termo empírico e só pode ser tomado nesta significação, somos sim tocados, através de um sentimento, por algo que, feita a reflexão, determinados os conceitos, aplicados - pelo poder fundamental da imaginação - os conceitos às sensações, chamamos de coisas-em-si, mas já desde este ponto de vista empírico; do ponto de vista transcendental, reflexionante, subjetivo, este sentimento é só um sentimento, isto é, algo simplesmente subjetivo, que remete a um Não-Eu, que representamos como o limite da ação prática no mundo.

Quando Kant fala de coisas-em-si do ponto de vista filosófico, o sentido do conceito distingue-se daquele no sentido empírico. Nesse, coisas-em-si são objetos que existem prontos independente e anteriormente ao sujeito; naquele, fala-se apenas de númenos, 
de objetos pensados, não de uma existência objetiva (que só diz respeito ao ponto de vista empírico). 0 númeno é o objeto posto pelas leis necessárias de nossa razão, que acrescentamos aos fenômenos para dar-lhes objetividade. Fichte mantém este sentido, pois com ele podemos explicar como objetos parecem independentes de nossas representações e ainda assim não são entidades transcendentes.

Desta forma, a rejeição de Fichte se refere ao conceito de algo que não pode ser conhecido, pois indica uma entidade que transcende o âmbito de acesso e legislação do Eu. Mas o conceito é mantido no segundo sentido exposto: o de um pensamento necessário de objetos que não podem ser identificados ao $\mathrm{Eu}$, mas que, ao contrário, devem ser pensados como limite de sua atividade, sendo para o Eu um Não-Eu. A oposição entre Eu e Não-Eu, diz Fichte, é conditio sine qua non para o conhecimento do $\mathrm{Eu}$, posto que conhecer é determinar, portanto, distinguir precisamente que algo é diferente de algo outro. Esse Não-Eu é, pois, o pensamento necessário (númeno) de algo que se opõe absolutamente ao $\mathrm{Eu}$, mas, enquanto tal, é ainda um pensamento do Eu. $\mathrm{O}$ limite ou choque (Anstoss) à atividade do Eu, posta pelo Eu como a existência de um Não-Eu, não se dá por nenhum conhecimento propriamente dito, mas por sentimento (Gefühl). Algo externo ao Eu, que o limita, é um pensamento necessário para explicar a limitação sentida pela atividade prática do Eu, ou melhor, da "percepção imediata da mesma"11.

O termo sentimento aparece justamente como uma alteração do termo usado por Kant nos trechos que fomentaram a polêmica em torno da coisa-em-si, a saber, sensação (Empfindung). A sensação, enquanto tal, só existe na relação com um objeto; o sentimento, a contrario, não remete a nada, em sua origem, além do Eu, por isso Fichte chama-o sentimento original (ursprüngliche Gefühl). Não entender este sentimento como absolutamente originário, isto é, postular algo anterior a ele, que o causa, é o próton pseudós de céticos e dogmáticos:

Pretender explicar este sentimento original a partir da operação de um algo é o dogmatismo dos kantianos, (...) e que eles bem gostariam de atribuir a Kant. Este seu algo é necessariamente a enfadonha coisa em si. Toda explicação transcendental tem um fim no sentimento imediato ${ }^{12}$.

o que ainda vale ser mencionado aqui, é: a solução fichtiana, isto é, a volta aos sentimentos, pela reflexão, para resolver o problema da coisa-em-si tal como ele foi elaborado por Jacobi, sem contudo deixar de responder, de outro modo, ao problema de Garve e a outros tantos problemas livremente admitidos por Kant, esta solução, dizíamos, aproxima Fichte de Rousseau, concretamente do Discurso sobre a origem da desigualdade entre os homens, o que trataremos a seguir.

\section{Fichte leitor de Rousseau - crítica do sentimento puro}

Pretendemos mostrar aqui que (1) Fichte declara uma filiação à filosofia de Rousseau, (2) através do elogio ao esforço de fundar a filosofia sobre o sentimento; no entanto, (3) Fichte é um leitor crítico de Rousseau, isso fica evidente na (4) crítica fichtiana ao erro de Rousseau, que, surpreendentemente, (5) é a declaração de uma radicalização do projeto rousseauísta; esta interpretação do Fichte leitor de Rousseau é, ainda, extremamente reveladora da (6) concepção fichtiana da filosofia e do (7) "discurso do 
método" fichtiano, que é, na verdade, (8) o fundamento da crítica e da radicalização fichtiana a Rousseau.

Desta investigação, extraímos as seguintes conclusões: (1) a filiação a Rousseau está baseada na pretensão fichtiana de levar a cabo o projeto filosófico de Rousseau, a saber, a ciência suprema enquanto conhecimento de si por meio de um conhecimento do sentimento-de-si, a (2) crítica de Fichte a Rousseau, isto é, o ponto preciso de discordância de Fichte em relação a Rousseau, está baseada na acusação por parte daquele (Fichte) de que este (Rousseau) não apreendeu que o conhecimento completo de si-mesmo não é dado simplesmente no conhecimento dos sentimentos, mas apenas no conhecimento do sentimento-de-si mais primordial, puro, nas palavras de Fichte, no "sentimento originário"; ainda segundo Fichte, e aqui temos a "teoria do erro" fichtiana, (3) o sentimento é sempre verdadeiro, consistindo todo erro no juízo, e isto ocorre quando o juízo não está fundamentado em um "sentimento puro", mas em sentimentos "mistos"; para Fichte, (4) os erros de Rousseau explicam-se pelo fato de que os seus juízos basearam-se em sentimentos mistos; o (5) método da verdade de Fichte consiste, então, em radicalizar o método rousseauísta, a saber, radicalizar o conhecimento-de-si pelos sentimentos como método da verdade, e da verdade da "ciência sublime", isto se dá, como apontamos acima, pela busca de um sentimento primordial, originário, que revele o conhecimento-de-si-completo e, portanto, do conhecimento da verdade última.

Se esta nossa leitura estiver correta, devemos concluir sobre a filosofia de Fichte: (1) Ela é, essencialmente, uma filosofia do sentimento, no sentido rousseauísta do termo; (2) Fichte filia-se à tradição filosófica inaugurada por Rousseau de busca da verdade fundamental através da análise dos sentimentos; (3) Fichte distancia-se de Rousseau e, portanto, elabora um projeto próprio de investigação, ao criticar este por não ter sido mais radical em sua investigação verdadeira, (4) este projeto fichtiano é o seguinte: a verdade será encontrada na investigação de um sentimento originário, fundamental; desta forma, (5) a Doutrina-da-ciência de Fichte é, fundamentalmente, uma Doutrina-dosentimento - Gefühlslehre.

Uma vez apresentados os objetivos deste nosso trabalho, convém declararmos como provaremos as hipóteses mencionadas: por uma análise de um trecho do Discurso sobre as ciências e as artes, e, em seguida, de uma análise de um trecho da obra de Fichte no qual ele comenta Rousseau, a saber, em Sobre a destinação do sábio.

Comecemos com Rousseau. $O$ trecho a se analisar é o seguinte:

ò, virtude, ciência sublime das almas simples, são necessárias tantas penas e tanto estrondo para te conhecer? Teus princípios, não estão gravados em todos os corações? Não basta para aprender tuas leis voltar a entrar em si-mesmo e escutar a voz da consciência no silêncio das paixões? Eis aí a verdadeira filosofia, aprendamos a nos bastar com ela. ${ }^{13}$

19 Na primeira oração, Rousseau diz: “Ò, virtude, ciência sublime das almas simples...", eis a declaração de Rousseau sobre o que é a investigação da virtude: é a "ciência sublime". A oração seguinte é uma pergunta retórica sobre o "método adequado" desta ciência sublime que foi apresentada, nos seguintes termos: "são necessárias tantas penas e tanto estrondo para te conhecer?". O segredo da oração está em compreender em que consiste as "penas" e o "estrondo" e em quem Rousseau está pensado ao fazer esta crítica; este segredo será revelado ainda nesta passagem. 
20 Antes, porém, diz o filósofo: "Teus princípios, não estão gravados em todos os corações?", isto nós lemos do seguinte modo: Os princípios da ciência sublime, que é a virtude, devem ser íntimos a todos homens. Com isso Rousseau está preparando a afirmação seguinte, que é uma definição do método verdadeiro de descoberta desta ciência sublime; escutemos novamente a frase: "Não basta para aprender tuas leis voltar a entrar em si-mesmo e escutar a voz da consciência no silêncio das paixões?". Em primeiro lugar, constatemos que a presente afirmação é uma contraposição àquela pergunta retórica anteriormente levantada ("são necessárias tantas penas e tanto estrondo para te conhecer?"), que neste contraposto encontra a solução do segredo do significado de seus termos e em quem Rousseau está pensando, a saber: as penas e o estrondo opõe-se a este outro modo de investigação, fundado na reflexão ("voltar a entra em si-mesmo") e no conhecimento dos sentimentos ("escutar a voz da consciência no silêncio das paixões") ${ }^{14}$. 0 projeto rousseauísta funda-se, portanto, no método reflexivo da investigação dos sentimentos. 0 que são, então, as penas e o estrondo da concepção filosófica oposta? Só pode ser as meticulosidades escolásticas (penas) e a glorificação da razão (estrondo), na medida em que elas representam o rigor lógico da combinação de conceitos e na pretensão metafísica de provar e demonstrar racionalmente os dogmas transcendentes. Em outras palavras, mais esquemáticas, as penas e o estrondo referem-se à vaidade e ao método racionalista, racionalismo significado aqui como estrondo enquanto confiança excessiva nos poderes da razão.

21 Por fim, a passagem de Rousseau declara ainda mais dois pontos: (1) O método reflexivo em busca da verdade pelo sentimento é a "verdadeira filosofia", a ciência sublime e (2), por isso, é um erro contrapor esta verdadeira filosofia à uma pretensa ciência da essência dos dogmas teológicos (Deus, liberdade, mundo) por meio da, digamos, mera análise lógica: "aprendamos a nos bastar com ela".

Passemos agora ao comentário fichtiano da passagem de Rousseau acima analisada. Diz Fichte:

o que Rousseau tem de verdadeiro, se funda diretamente em seu sentimento; e seu conhecimento tem portanto o defeito de todo conhecimento fundado em um mero sentimento não desenvolvido; que em parte é inseguro, porque não dá conta completamente de seu sentimento; em parte o verdadeiro se mescla com o nãoverdadeiro, porque um juízo fundado em um sentimento não desenvolvido apresenta como sendo equivalente o que não o é. Isto é, o sentimento nunca se engana, mas o juízo se equivoca quando interpreta de modo incorreto o sentimento e toma um sentimento misto por um puro. ${ }^{15}$

Voltemos ao método de interpretação para poder extrair desse trecho todas as hipóteses de leitura que apresentamos no início deste texto. Fichte inicia com um elogio a Rousseau, pois este filósofo alcançou, de alguma forma, uma verdade ("O que Rousseau tem de verdadeiro..."), para em seguida especificar qual é esta verdade que Rousseau encontrou: os juízos baseados em seus sentimentos (“... [a verdade de Rousseau] se funda diretamente em seus sentimentos.").

Após esta declaração de filiação, porém, Fichte começa a apresentar as razões de sua crítica a Rousseau; Fichte diz: "seu conhecimento tem portanto o defeito de todo conhecimento fundado em um mero sentimento não desenvolvido", o que entendemos por: o conhecimento adquirido por Rousseau, a saber, de seus sentimentos, é, contudo, falho, isto por duas razões: (1) Rousseau não conseguiu explicar completamente a sua fonte da verdade, a saber, o sentimento ("em parte é inseguro, porque não dá conta completamente de seu sentimento"), e, em decorrência disso, (2) mesclou o verdadeiro 
com falso ("em parte o verdadeiro se mescla com o não-verdadeiro"), pois "um juízo fundado em um sentimento não desenvolvido apresenta como sendo equivalente o que não o é"; em outras palavras, segundo Fichte, Rousseau, a despeito de ter encontrados verdades, as perdeu de vista ao misturá-las com falsidades; e a frase de Fichte acrescenta a razão segundo a qual Rousseau embaralhou verdades e falsidades: ele emitiu juízos fundados em sentimentos, o que, como vimos, é o mérito maior de Rousseau, segundo Fichte, mas tão-somente sobre "sentimentos mistos".

Resta explicar, agora, o que Fichte está entendendo por "sentimentos mistos", e isso é fornecido pelo filósofo na frase seguinte, que diz: "o sentimento nunca se engana, mas o juízo se equivoca quando interpreta de modo incorreto o sentimento e toma um sentimento misto por um puro". A primeira observação a que devemos nos atentar é à distinção aqui formulada por Fichte entre sentimento misto e sentimento puro. Com esta distinção, Fichte está propondo que há um sentimento fundamental, essencial, originário, isto é, "sentimento puro"; deste sentimento, derivam todos os demais; temos, pois, um sentimento fundamental e uma multiplicidade de sentimentos que daquele sentimento originário deriva, estes sentimentos derivados misturam-se uns ao outros, formando assim sentimentos mistos.

Ora, uma vez explicada a distinção entre sentimento puro e sentimentos mistos, voltemos à frase de Fichte: ela afirma uma teoria da verdade e seu inverso complementar, uma teoria de erro. 0 que é, então, a verdade, para Fichte? - 0 juízo fundado no sentimento puro. o que é, por sua vez, o erro? - o juízo fundado em um sentimento misto, que é falsamente tomado por sentimento puro.

Por fim, disto que vimos, podemos extrair as seguintes conclusões, para uma interpretação de Fichte: O projeto fichtiano de um saber absoluto, isto é, de uma doutrina-da-ciência, tem de ser entendido como, primordialmente, uma doutrina-dossentimentos, na medida em que a fonte da verdade, e da verdade suprema, é o sentimento; nisto, Fichte é um discípulo de Rousseau. Esta doutrina-da-ciência enquanto doutrina-dos-sentimentos, no entanto, não é, como parece ser em Rousseau, uma investigação sobre os sentimentos em geral, mas, antes, uma investigação de um sentimento singular, a saber, do sentimento originário ou puro, e aqui está condensada a crítica fichteana a Rousseau, na medida que Fichte defende que a filosofia daquele erra ao confundir sentimentos mistos por um sentimento fundamental.

28 A busca deste sentimento primordial, por parte de Fichte, não será trilhada em um método diverso ao de Rousseau mas, ao contrário, na radicalização deste método, que é, em poucas palavras, uma investigação reflexiva que procura a essência do homem em sua consciência de si, mas em sua radicalização por parte de Fichte este método passa a ter um objeto privilegiado, a saber, um sentimento originário a partir do qual se possa analisar e explicitar toda a derivação e os limites dos demais sentimentos, sem, portanto, confundi-los.

Encontramos ao fim, neste Fichte rousseauísta, um avanço de tonalidade kantiana, na medida em que o método e o projeto rousseauísta, adotados por Fichte, procura ser radicalizado por meio de uma crítica dos sentimentos, isto é, uma investigação transcendental que procura determinar os limites e a validade do discurso filosófico fundado na reflexão sobre a consciência e o conhecimento-de-si enquanto conhecimento de um sentimento-de-si? 

Meiner. tradução de Ricardo Barbosa. In: Revista Analytica, Rio de Janeiro, vol. 13 no 1, 2009, p. 285-306. Disponível em: [http://www.analytica.inf.br/]. Acesso em: 10 de Julho. 2013. - - - - (1992) Cartas sobre a filosofia kantiana (excertos), in: GIL, F., (coord.), Recepção da crítica da razão pura: antologia de escritos sobre Kant 1786-1844, 85-109.

50 - - - - (1992) Ensaio sobre uma nova teoria da faculdade humana de representação (excertos). Trad. port.: Irene Borges Duarte, in: GIL, F., Recepção da crítica da razão pura: antologia de escritos sobre Kant 1786-1844, 173-203. 
51 ROUSSEAU, J.-J. (1964) Discours sur les sciences et les arts; Discours sur l'origine et les fondements de l'inégalité parmi les hommes. Oeuvres complètes, Paris: Gallimard.

- - - - (1978) Discurso sobre as ciências e as artes. 2. ed. Trad. L. Santos Machado. São Paulo: Nova Cultural.

ESPÍNDOLA, A. (2007) “O lugar dos sentimentos na ética de Jean-Jacques Rousseau”, REVISTA DE FILOSOFIA, 19/25, 345-360.

\section{NOTAS}

1. DRUMMOND, C. de A., A noite dissolve os homens.

2. JACOBI 2006; 1995; FERREIRA 1992; CASSIRER 1993; CRUZ CRUZ 1986; GUILLERMIT 1982; BONACINNI 2003: 41-9.

3. $\mathrm{KrV} \mathrm{B} 1$.

4. $\mathrm{KrV}$ B235 e A190.

5. Neste ponto, B 1, o termo usado é tocar ou mover: “[...] die unsere Sinne rühren und teils von selbst Vorstellungen bewirken...” (grifos nossos). No §1 da Estética Transcendental, aparece o termo afetar: "Diese findet aber nur statt, so fern uns der Gegenstand gegeben wird; dieses aber ist wiederum, uns Menschen wenigstens, nur dadurch möglich, daß er das Gemüt auf gewisse Weise affiziere. [...] Die Fähigkeit (Rezeptivität), Vorstellungen durch die Art, wie wir von Gegenständen affiziert werden, zu bekommen, heißt Sinnlichkeit", B 33 (grifos nossos). Na Segunda Analogia, B 235 [“...wie Dinge an sich selbst (ohne Rücksicht auf Vorstellungen, dadurch sie uns affizieren) sein mögen...” (grifos nossos)] e no capítulo Do princípio da distinção de todos os objectos em geral em fenômenos e númenos, B 309 ["denn durch bloße Anschauung wird gar nichts gedacht, und, daß diese Affektion der Sinnlichkeit in mir ist...” (grifos nossos)], novamente aparece o termo afecção.

6. JACOBI 2006: 301-2.

7. JACOBI 2006: 307: "Pergunto, como é possível conciliar a suposição de objetos que impressionam nossos sentidos e que, deste modo, suscitam representações, com uma doutrina que pretende reduzir a nada todos os fundamentos que apóiam esta mesma suposição?"

8. REINHOLD 2009: 291-306; cf. também 1992a, 1992b e 2004.

9. REIHOLD 2009: p. 194.

10. KANT 1987: 175: "Esta obra é um sistema do idealismo transcendente (ou, como ele traduz, superior)". Acusação que Kant interpreta do seguinte modo: "todo o conhecimento a partir dos sentidos e da experiência nada mais é do que ilusão, e a verdade unicamente existe nas ideias do entendimento puro e da razão pura".

11. FICHTE 1984: 353.

12. Idem, grifos nossos.

13. ROUSSEAU 1964: 30 .

14. ESPÍNDOLA 2007: 345-60.

15. BG, GA I/3, 61; 1999: 42-3. 


\section{RESUMOS}

The article aims to outline the importance of the concept of feeling at the thought of Fichte in the years 1793-1797. Discuss the theme of feeling in Fichte, in two ways: 1 . The function that has the feeling that Fichte gives the answer to the "problem of the thing-in-itself", particularly the discussions around this topic by the first readers Kantian, including: Garve, Jacobi, and Reinhold. 2. The assimilation and critique of Fichte to the theme of feeling in Rousseau.

\section{ÍNDICE}

Keywords: Fichte, feeling, Garve, Jacobi, Reinhold, Rousseau

\section{AUTOR}

\section{GLAUBER CESAR KLEIN}

Universidade Federal do Paraná 